\title{
WEAKLY CONVERGENT SEQUENCE COEFFICIENT OF PRODUCT SPACE
}

\author{
GUANG-LU ZHANG
}

(Communicated by Palle E. T. Jorgensen)

\begin{abstract}
W. L. Bynum introduced the weakly convergent sequence coefficient $\mathrm{WCS}(X)$ of the Banach space $X$ as $\mathrm{WCS}(X)=\sup \{M$ : for each weakly convergent sequence $\left\{x_{n}\right\}$ in $X$, there is some $y \in \overline{c o}\left(\left\{x_{n}\right\}\right)$ such that $M$. lim sup $\left.\left\|x_{n}-y\right\| \leq A\left(\left\{x_{n}\right\}\right)\right\}$. We consider the weakly convergent sequence coefficient of the $l_{p}$-product space $Z=\left(\prod_{i=1}^{n} X_{i}\right)_{l_{p}}$ of the finite non-Schur space $X_{1}, \ldots, X_{n}$ and show that $\operatorname{WCS}(Z)=\min \left\{\operatorname{WCS}\left(X_{i}\right): 1 \leq i \leq n\right\}$.
\end{abstract}

\section{INTRODUCTION}

Let $X$ be a Banach space and $\left\{x_{n}\right\}$ a sequence of $X$. For $x \in X$, set $r\left(x,\left\{x_{n}\right\}\right)=\lim \sup _{n}\left\|x_{n}-x\right\| . \quad A\left(\left\{x_{n}\right\}\right)=\lim _{n} \sup \left\{\left\|x_{i}-x_{j}\right\|: i, j \geq n\right\}$ and $r\left(\left\{x_{n}\right\}\right)=\inf \left\{r\left(x,\left\{x_{n}\right\}\right): x \in \overline{c o}\left(\left\{x_{n}\right\}\right)\right\}$ are called the asymptotic diameter of $\left\{x_{n}\right\}$ and the Chebyshev radius of $\left\{x_{n}\right\}$ relative to $\overline{\mathrm{co}}\left(\left\{x_{n}\right\}\right)$, respectively, where $\overline{c o}\left(\left\{x_{n}\right\}\right)$ denotes the closed convex hull of $\left\{x_{n}\right\}$. If $A\left(\left\{x_{n}\right\}\right)=$ $\lim _{n} \inf \left\{\left\|x_{i}-x_{j}\right\|: i, j \geq n, i \neq j\right\}$, then the sequence $\left\{x_{n}\right\}$ is called the asymptotic equidistant sequence.

In order to study the normal structure of Banach spaces, Bynum [1] introduced the weakly convergent sequence coefficient $\operatorname{WCS}(X)$ for a reflexive Banach space $X$ as follows:

$\operatorname{WCS}(X)=\sup \left\{M:\right.$ for each weakly convergent sequence $\left\{x_{n}\right\}$,

there is some $y \in \overline{\mathrm{co}}\left(\left\{x_{n}\right\}\right)$ such that

$$
\left.M \cdot \lim \sup _{n}\left\|x_{n}-y\right\| \leq A\left(\left\{x_{n}\right\}\right)\right\} .
$$

It is easy to prove that (see [2])

$$
\begin{aligned}
\operatorname{WCS}(X)=\inf \left\{A\left(\left\{x_{n}\right\}\right) / r\left(\left\{x_{n}\right\}\right):\right. & \left\{x_{n}\right\} \text { a weakly but not } \\
& \text { strongly convergent sequence in } X\} .
\end{aligned}
$$

But, because of the indefiniteness of $y$ in expression (1) and the existence of $r\left(\left\{x_{n}\right\}\right)$ in the denominator of expression (2), it is inconvenient to apply and

Received by the editors January 2, 1990.

1991 Mathematics Subject Classification. Primary 46B20.

Key words and phrases. Asymptotic equidistant sequence, weakly convergent sequence coefficient. 
calculate $\operatorname{WCS}(X)$. We will improve expressions (1) and (2) on $\operatorname{WCS}(X)$ and use new expressions of $\operatorname{WCS}(X)$ to discuss the weakly convergent sequence coefficient of the $l_{p}$-product space of finite non-Schur Banach spaces.

In $\S 1$ we introduce the notion of the asymptotic equidistant sequence and show some results on it since we will use it to improve the expressions of $\mathrm{WCS}(X)$. In $\S 2$ we give four new expressions of $\mathrm{WCS}(X)$, which are better than (1) and (2). Finally, in $\S 3$, we give a result on the weakly convergent sequence coefficient of the $l_{p}$-product space of finite non-Schur Banach spaces.

We always denote the set of natural numbers by $\mathscr{N}$ and we say that $x_{n} \stackrel{w}{\rightarrow} x$ to denote $\left\{x_{n}\right\}$ weakly converges to $x$.

\section{Asymptotic EQuidistant SEQUence}

In this section we always consider $X$ to be infinite-dimensional Banach space. For a sequence $\left\{x_{n}\right\}$ in $X$, we express $\lim _{n} \inf \left\{\left\|x_{i}-x_{j}\right\|: i, j \geq n, i \neq j\right\}$ by $A_{1}\left(\left\{x_{n}\right\}\right)$.

Definition 1. A sequence $\left\{x_{n}\right\}$ in $X$ is said to be an asymptotic equidistant sequence if $A_{1}\left(\left\{x_{n}\right\}\right)=A\left(\left\{x_{n}\right\}\right)$.

It is clear that if $\left\{x_{n}\right\}$ is either strongly convergent or equidistant (i.e., for $i \neq j,\left\|x_{i}-x_{j}\right\|=$ constant $)$, then it is asymptotic equidistant.

In the following, we prove that we can choose an asymptotic equidistant subsequence from a bounded sequence.

Proposition 1. Let $\left\{x_{n}\right\}$ be a bounded sequence in $X$ and

$$
\begin{array}{r}
d=\sup \left\{d^{\prime}: \text { there exists a subsequence }\left\{x_{n_{i}}\right\} \text { of }\left\{x_{n}\right\}\right. \\
\text { such that } \left.\left\|x_{n_{i}}-x_{n_{j}}\right\| \geq d^{\prime} \text { when } i \neq j\right\} .
\end{array}
$$

Then for every $\varepsilon>0$ there exists a subsequence $\left\{y_{k}\right\}$ of $\left\{x_{n}\right\}$ such that $d-\varepsilon<$ $\left\|y_{i}-y_{j}\right\|<d+\varepsilon$ when $i \neq j$.

Proof. For any $\varepsilon>0$, by definition of $d$, there exists a subsequence $\left\{x_{n_{k}}\right\}$ of $\left\{x_{n}\right\}$ such that $\left\|x_{n_{i}}-x_{n_{j}}\right\|>d-\varepsilon$ when $i \neq j$. For any subsequence $\left\{x_{n_{k}}(m)\right\}_{k=1}^{\infty}$ of $\left\{x_{n_{k}}\right\}$, if all distances from its first term $x_{n_{1}}(m)$ to the other terms, except those that are finite, are not smaller than $d+\varepsilon$, then the $x_{n_{1}}(m)$ is called a deleted point.

Consider the sequence $\left\{x_{n_{k}}\right\}$. If $x_{n_{1}}$ is a deleted point, then delete $x_{n_{1}}$ and all of the finite points whose distances to $x_{n}$ are smaller than $d+\varepsilon$. Let the rest be $\left\{x_{n_{k}}(1)\right\}$ according to the original order. If $x_{n_{1}}(1)$ is a deleted point also, then delete $x_{n_{1}}(1)$ and the associated finite points and denote the rest by $\left\{x_{n_{k}}(2)\right\}$ according to the original order. If $x_{n_{1}}(2)$ is a deleted point, delete $x_{n_{1}}(2)$ and the associated finite points continuously, etc. But this process cannot proceed indefinitely, or else we get a sequence $x_{n_{1}}, x_{n_{1}}(1), x_{n_{1}}(2), \ldots$ of deleted points, any two points of which have distance $\geq d+\varepsilon$. This is a contradiction to the definition of $d$. So the sequence $\left\{x_{n_{k}}\right\}$ must have a point which is not deleted. Note it by $x_{n_{1}}(1)$ and let $\left\{x_{n_{k}}(1)\right\}$ be a subsequence of $\left\{x_{n_{k}}\right\}$ such that $\left\|x_{n_{1}}(1)-x_{n_{i}}(1)\right\|<d+\varepsilon$ for every $i>1$.

Continue to consider the sequence $x_{n_{2}}(1), x_{n_{3}}(1), \ldots$. As mentioned above, we also can get a point $x_{n_{2}}(2)$ from this sequence, which is not deleted, and a subsequence $x_{n_{2}}(2), x_{n_{3}}(2), \ldots$ of this sequence such that $\left\|x_{n_{2}}(2)-x_{n_{i}}(2)\right\|<$ $d+\varepsilon$ for every $i>2$. Continue this process for the sequence $x_{n_{3}}(2), x_{n_{4}}(2), \ldots$, 
etc. When this process is continued infinitely, we can finally get a subsequence $\left\{x_{n_{k}}(k)\right\}_{k=1}^{\infty}$ of $\left\{x_{n_{k}}\right\}$ such that $\left\|x_{n_{i}}(i)-x_{n_{j}}(j)\right\|<d+\varepsilon$ when $i \neq j$. The proof of the proposition is finished by letting $y_{k}=x_{n_{k}}(k)$.

Proposition 2. Let $\left\{x_{n}\right\}$ be a bounded sequence in $X$. Then there exists an asymptotic equidistant subsequence $\left\{y_{k}\right\}$ of $\left\{x_{n}\right\}$ such that $A_{1}\left(\left\{x_{n}\right\}\right) \leq A\left(\left\{y_{k}\right\}\right)$ $\leq A\left(\left\{x_{n}\right\}\right)$.

Proof. Let $d_{1}=\sup \left\{d^{\prime}\right.$ : there exists a subsequence $\left\{x_{n_{i}}\right\}$ of $\left\{x_{n}\right\}$ such that $\left\|x_{n_{i}}-x_{n_{j}}\right\| \geq d^{\prime}$ for $\left.i \neq j\right\}$. Then $A_{1}\left(\left\{x_{n}\right\}\right) \leq d_{1} \leq A\left(\left\{x_{n}\right\}\right)$. By Proposition 1, there exists a subsequence $\left\{x_{n}(1)\right\}$ of $\left\{x_{n}\right\}$ such that $d_{1}-1<\left\|x_{i}(1)-x_{j}(1)\right\|<$ $d_{1}+1$ for $i \neq j$. Let $d_{2}=\sup \left\{d^{\prime}\right.$ : there exists a subsequence $\left\{x_{n_{i}}(1)\right\}$ of $\left\{x_{n}(1)\right\}$ such that $\left\|x_{n_{i}}(1)-x_{n_{j}}(1)\right\| \geq d^{\prime}$ for $\left.i \neq j\right\}$. Then $A_{1}\left(\left\{x_{n}\right\}\right) \leq$ $d_{2} \leq d_{1}$ and, by Proposition 1 also, there exists a subsequence $\left\{x_{n}(2)\right\}$ of $\left\{x_{n}(1)\right\}$ such that $d_{2}-\frac{1}{2}<\left\|x_{i}(2)-x_{j}(2)\right\|<d_{2}+\frac{1}{2}$ for $i \neq j$. Generally, if $d_{m}=\sup \left\{d^{\prime}:\right.$ there exists a subsequence $\left\{x_{n_{i}}(m-1)\right\}$ of $\left\{x_{n}(m-1)\right\}$ such that $\left\|x_{n_{i}}(m-1)-x_{n_{j}}(m-1)\right\| \geq d^{\prime}$ for $\left.i \neq j\right\}$, then $A_{1}\left(\left\{x_{n}\right\}\right) \leq d_{m} \leq d_{m-1}$ and, by Proposition 1, there exists a subsequence $\left\{x_{n}(m)\right\}$ of $\left\{x_{n}(m-1)\right\}$ such that $d_{m}-1 / m<\left\|x_{i}(m)-x_{j}(m)\right\|<d_{m}+1 / m$ for $i \neq j$. Thus we can obtain a real sequence $\left\{d_{m}\right\}$ satisfying

$$
A_{1}\left(\left\{x_{n}\right\}\right) \leq \cdots \leq d_{m} \leq d_{m-1} \leq \cdots \leq d_{1} \leq A\left(\left\{x_{n}\right\}\right),
$$

and a series of sequences $\left\{x_{n}(1)\right\},\left\{x_{n}(2)\right\}, \ldots,\left\{x_{n}(k)\right\}, \ldots$, where each sequence is a subsequence of the last one, satisfying

$$
d_{m}-1 / m<\left\|x_{i}(m)-x_{j}(m)\right\|<d_{m}+1 / m
$$

for each $m \in \mathscr{N}$ and $i \neq j$. Let $y_{k}=x_{k}(k)$. Then $\left\{y_{k}\right\}$ satisfies the requirement of the proposition. Indeed, let $d=\lim _{m} d_{m}$; it is sufficient to prove that $A_{1}\left(\left\{y_{k}\right\}\right)=A\left(\left\{y_{k}\right\}\right)=d$. For every $\varepsilon>0$, by (4), there is $N \in \mathscr{N}$ such that $d-\varepsilon<d_{k}-1 / k<d_{k}+1 / k<d+\varepsilon$ when $k>N$. Hence, when $i, j>N$ and $i \neq j, d-\varepsilon<\left\|y_{i}-y_{j}\right\|<d+\varepsilon$, which shows that $A_{1}\left(\left\{y_{k}\right\}\right)>d-\varepsilon$ and $A\left(\left\{y_{k}\right\}\right)<d+\varepsilon$. By the arbitrariness of $\varepsilon, A_{1}\left(\left\{y_{k}\right\}\right)=A\left(\left\{y_{k}\right\}\right)=d$ holds.

Recall the famous Riesz Lemma: for every $\varepsilon>0$, there exists a sequence $\left\{x_{n}\right\}$ in $S(X)$, the unit sphere of $X$, such that $\left\|x_{i}-x_{j}\right\|>1-\varepsilon$ when $i \neq j$. Hence, by Proposition 2, there exist asymptotic equidistant sequences $\left\{x_{n}\right\}$ in $S(X)$ such that $A\left(\left\{x_{n}\right\}\right)>1-\varepsilon$ for every $\varepsilon>0$. In addition, reviewing the parameter $\bar{J}(X)^{[3,4]}$ of $X$,

$$
\bar{J}(X)=\sup \{r>0: S(X) \text { contains an infinite } r \text {-separated set }\},
$$

we furthermore have

Proposition 3. For every $\varepsilon>0$, there exists an asymptotic equidistant sequence $\left\{x_{n}\right\}$ in $S(X)$ such that $\bar{J}(X)-\varepsilon \leq A\left(\left\{x_{n}\right\}\right) \leq \bar{J}(X)$.

Proof. Obvious.

Considering a weakly convergent sequence, we have the following result.

Proposition 4. Let $x_{n} \stackrel{w}{\rightarrow} z$ and $\lim \sup _{n}\left\|x_{n}-z\right\|=a$. Then the sequence $\left\{x_{n}\right\}$ has an asymptotic equidistant subsequence $\left\{y_{k}\right\}$ such that $A\left(\left\{y_{k}\right\}\right) \geq a$.

Proof. Through choice of subsequence, we can assume that $\lim \left\|x_{n}-z\right\|=a$. Then it follows that $A\left(\left\{y_{k}\right\}\right) \geq a$ for every asymptotic equidistant subsequence 
$\left\{y_{k}\right\}$ of $\left\{x_{n}\right\}$. Otherwise, if $A\left(\left\{y_{k}\right\}\right)<a$ for some subsequence $\left\{y_{k}\right\}$ of $\left\{x_{n}\right\}$, then, for sufficiently large $n \in \mathscr{N}$, the diameter of $\overline{\operatorname{co}}\left(\left\{y_{k}\right\}_{n}^{\infty}\right)$ is smaller than $a$. This contradicts the fact $z \in \overline{\mathrm{co}}\left(\left\{y_{k}\right\}_{n}^{\infty}\right)$.

Remark 1. For a non-Schur space $X$ (i.e., weak and strong convergence of a sequence in $X$ do not coincide), there exist sequences in $S(X)$ which weakly converge to zero. By the proof of Proposition 4, for a sequence $\left\{x_{n}\right\}$ in $S(X)$ with $x_{n} \stackrel{w}{\rightarrow} 0$, any of its asymptotic equidistant subsequences $\left\{y_{k}\right\}$ satisfies $A\left(\left\{y_{k}\right\}\right) \geq 1$.

\section{IMPROVEMENTS OF EXPRESSIONS OF THE WCS $(X)$}

In order to study the weakly convergent sequence coefficient of product space we first give some improvements of expressions (1) and (2) on WCS $(X)$. It is assumed below that all Banach spaces are non-Schur spaces, and the area of spaces we discuss is extended from reflexive to this type of spaces. For a nonSchur space $X, \operatorname{WCS}(X)$ is defined by (1) or (2) (both are equivalent) also.

\section{Theorem 1.}

$$
\mathrm{WCS}(X)=\sup \left\{M: x_{n} \stackrel{w}{\rightarrow} u \Rightarrow M \cdot \limsup _{n}\left\|x_{n}-u\right\| \leq A\left(\left\{x_{n}\right\}\right)\right\} .
$$

Proof. For convenience, let

$$
W(X)=\sup \left\{M: x_{n} \stackrel{w}{\rightarrow} u \Rightarrow M \cdot \limsup _{n}\left\|x_{n}-u\right\| \leq A\left(\left\{x_{n}\right\}\right)\right\} .
$$

Since $x_{n} \stackrel{w}{\rightarrow} u$ implies $u \in \overline{\mathrm{co}}\left(\left\{x_{n}\right\}\right)$, it is easy to see that $W(X) \leq \mathrm{WCS}(X)$. Now let $x_{n} \stackrel{w}{\rightarrow} u$. Due to separableness of $\overline{\mathrm{co}}\left(\left\{x_{n}\right\}\right)$, we can choose a subsequence $\left\{x_{n_{k}}\right\}$ of $\left\{x_{n}\right\}$ by the diagonal method such that $\lim _{k}\left\|x_{n_{k}}-u\right\|=$ lim $\sup _{n}\left\|x_{n}-u\right\|$ and there exist $\lim _{k}\left\|x_{n_{k}}-y\right\|$ for all $y \in \overline{c o}\left(\left\{x_{n}\right\}\right)$. For each $k \geq 1$, consider the sequence $\left\{x_{n_{j}}: j \geq k\right\}$. For any $\varepsilon>0$, by definition of $\operatorname{WCS}(X)$, there exists $y_{k} \in \overline{\operatorname{co}}\left(\left\{x_{j}: j \geq k\right\}\right)$ such that

$$
(\mathbf{W C S}(X)-\varepsilon) \cdot \lim \sup _{j}\left\|x_{n_{j}}-y_{k}\right\| \leq A\left(\left\{x_{n_{j}}: j \geq k\right\}\right) \leq A\left(\left\{x_{n_{j}}\right\}\right) .
$$

Notice that $y_{k} \stackrel{w}{\rightarrow} u$ and by weakly lower semicontinuity of the functional $\lim \sup _{j}\left\|x_{n_{j}}-y\right\|$, we have

$$
\begin{aligned}
(\mathrm{WCS}(X)-\varepsilon) \cdot \lim \sup _{n}\left\|x_{n}-u\right\| & =(\mathrm{WCS}(X)-\varepsilon) \cdot \lim _{j}\left\|x_{n_{j}}-u\right\| \\
& \leq(\mathrm{WCS}(X)-\varepsilon) \cdot \lim \sup _{k} \lim _{j}\left\|x_{n_{j}}-y_{k}\right\| \\
& \leq A\left(\left\{x_{n_{j}}\right\}\right) \leq A\left(\left\{x_{n}\right\}\right) .
\end{aligned}
$$

This means that $\operatorname{WCS}(X)-\varepsilon \leq W(X)$. By the arbitrariness of $\varepsilon$ and the discussion above, we have shown that $\operatorname{WCS}(X)=W(X)$.

\section{Theorem 2.}

(6)

$$
\mathrm{WCS}(X)=\inf \left\{\frac{A\left(\left\{x_{n}\right\}\right)}{r\left(u,\left\{x_{n}\right\}\right)}:\left\{x_{n}\right\} \text { weakly but not strongly converges to } u\right\} .
$$


Proof. Suppose

$$
A(X)=\inf \left\{\frac{A\left(\left\{x_{n}\right\}\right)}{r\left(u,\left\{x_{n}\right\}\right)}:\left\{x_{n}\right\} \text { weakly but not strongly converges to } u\right\}
$$

and $x_{n} \stackrel{w}{\rightarrow} u$ but $\left\{x_{n}\right\}$ does not strongly converge. For every $\varepsilon>0$, by Theorem 1 , $(\mathrm{WCS}(X)-\varepsilon) \cdot \lim \sup _{n}\left\|x_{n}-u\right\| \leq A\left(\left\{x_{n}\right\}\right)$, i.e.,

$$
\mathrm{WCS}(X)-\varepsilon \leq \frac{A\left(\left\{x_{n}\right\}\right)}{r\left(u,\left\{x_{n}\right\}\right)} \text {. }
$$

Hence $\operatorname{WCS}(X)-\varepsilon \leq A(X)$ and by the arbitrariness of $\varepsilon$ it follows that $\mathrm{WCS}(X) \leq A(X)$. On the other hand, if $x_{n} \stackrel{w}{\rightarrow} u$, then $A(X) \cdot \lim \sup _{n}\left\|x_{n}-u\right\| \leq$ $A\left(\left\{x_{n}\right\}\right)$, which implies that $A(X) \leq \mathrm{WCS}(X)$. Thus $\mathrm{WCS}(X)=A(X)$.

\section{Theorem 3.}

$$
\mathrm{WCS}(X)=\inf \left\{A\left(\left\{x_{n}\right\}\right):\left\{x_{n}\right\} \subset S(X) \text { and } x_{n} \stackrel{w}{\rightarrow} 0\right\} .
$$

Proof. Let $W_{0}(X)=\inf \left\{A\left(\left\{x_{n}\right\}\right):\left\{x_{n}\right\} \subset S(X)\right.$ and $\left.x_{n} \stackrel{w}{\rightarrow} 0\right\}$. By Theorem 2 , it is clear that $\mathrm{WCS}(X) \leq W_{0}(X)$. Conversely, for every $\varepsilon>0$, choose a sequence $\left\{x_{n}\right\}$ in $X$ such that $x_{n} \stackrel{w}{\rightarrow} u,\left\{x_{n}\right\}$ does not strongly converge, and $A\left(\left\{x_{n}\right\}\right) / r\left(u,\left\{x_{n}\right\}\right)<\mathrm{WCS}(X)+\varepsilon$. Let $y_{n}=x_{n}-u$. Then $y_{n} \stackrel{w}{\rightarrow} 0$. Choose a subsequence $\left\{y_{n_{k}}\right\}$ of $\left\{y_{n}\right\}$ such that $\lim _{k}\left\|y_{n_{k}}\right\|=\lim \sup _{n}\left\|y_{n}\right\|>0$ and each $y_{n_{k}} \neq 0$; then $z_{n_{k}}=y_{n_{k}} /\left\|y_{n_{k}}\right\| \in S(X)$ and $z_{n_{k}} \stackrel{w}{\rightarrow} 0$. Hence

$$
W_{0}(X) \leq A\left(\left\{z_{n_{k}}\right\}\right)=\frac{A\left(\left\{y_{n_{k}}\right\}\right)}{\lim _{k}\left\|y_{n_{k}}\right\|} \leq \frac{A\left(\left\{x_{n}\right\}\right)}{r\left(u,\left\{x_{n}\right\}\right)}<\operatorname{WCS}(X)+\varepsilon .
$$

By the arbitrariness of $\varepsilon$, it follows that $W_{0}(X) \leq \mathrm{WCS}(X)$ and so $\mathrm{WCS}(X)=$ $W_{0}(X)$.

From the results of Proposition 4 and Theorem 3 it follows immediately that

\section{Theorem 4.}

$$
\operatorname{WCS}(X)=\inf \left\{A\left(\left\{x_{n}\right\}\right):\left\{x_{n}\right\}\right. \text { an asymptotic equidistant }
$$
sequence in $S(X)$ and $\left.x_{n} \stackrel{w}{\rightarrow} 0\right\}$.

It is obvious that it is better to use and calculate expressions (5)-(8) on $\mathrm{WCS}(X)$ rather than expressions (1) and (2).

\section{ON PRODUCT SPACES}

The $l_{p}$-product space $Z=\left(\prod_{i=1}^{n} X_{i}\right)_{l_{p}}$ of Banach spaces $X_{1}, \ldots, X_{n}$ is, by definition, the set of all $z=\left(x_{1}, \ldots, x_{n}\right)$, where $x_{i} \in X_{i}$ for each $i \leq n$, either with the norm $\|z\|=\left(\sum_{i=1}^{n}\left\|x_{i}\right\|^{p}\right)^{1 / p}$ when $1 \leq p<\infty$, or with the norm $\|z\|=\max \left\{\left\|x_{i}\right\|: 1 \leq i \leq n\right\}$ when $p=\infty$. Now we use expression (8) to discuss $\mathrm{WCS}(Z)$.

Theorem 5. Let $1 \leq p \leq \infty, Z=\left(\prod_{i=1}^{n} X_{i}\right)_{l_{p}}$, and all $X_{i} \quad(1 \leq i \leq n)$ be non-Schur spaces. Then $\operatorname{WCS}(Z)=\min \left\{\mathrm{WCS}\left(X_{i}\right): 1 \leq i \leq n\right\}$.

Proof. Without loss of generality, we assume $n=2, X_{1}=X$, and $X_{2}=Y$. In view of $Z$ having subspaces isometric and isomorphic to $X$ and $Y$, it is clear that $\mathrm{WCS}(Z) \leq \min \{W C S(X), \mathrm{WCS}(Y)\}$. On the other hand, suppose $\left\{z_{n}\right\} \subset S(Z), z_{n} \stackrel{w}{\rightarrow} 0$, and $\left\{z_{n}\right\}$ is an asymptotic equidistant sequence. Note 
$z_{n}=\left(x_{n}, y_{n}\right)$, where $x_{n} \in X$ and $y_{n} \in Y$. Then $x_{n} \stackrel{w}{\rightarrow} 0$ and $y_{n} \stackrel{w}{\rightarrow} 0$. Let $\left\{n_{k}\right\}$ be a subsequence of the natural number sequence such that both $\left\{x_{n_{k}}\right\}$ and $\left\{y_{n_{k}}\right\}$ are asymptotic equidistant, and $\lim _{k}\left\|x_{n_{k}}\right\|=a$ and $\lim _{k}\left\|y_{n_{k}}\right\|=b$ both exist. For $1 \leq p<\infty$, notice that $\left\|x_{n_{k}}\right\|^{p}+\left\|y_{n_{k}}\right\|^{p}=1$ implies $a^{p}+b^{p}=1$. It is easy to prove

$$
\begin{aligned}
\lim _{\substack{i, j \rightarrow \infty \\
i \neq j}}\left\|z_{n_{i}}-z_{n_{j}}\right\| & =\lim _{\substack{i, j \rightarrow \infty \\
i \neq j}}\left(\left\|x_{n_{i}}-x_{n_{j}}\right\|^{p}+\left\|y_{n_{i}}-y_{n_{j}}\right\|^{p}\right)^{1 / p} \\
& \geq\left\{a^{p}[\operatorname{WCS}(X)]^{p}+b^{p}[\operatorname{WCS}(Y)]^{p}\right\}^{1 / p} \\
& \geq \min \{\operatorname{WCS}(X), \operatorname{WCS}(Y)\} .
\end{aligned}
$$

For $p=\infty$, notice that $\max \left\{\left\|x_{n_{k}}\right\|,\left\|y_{n_{k}}\right\|\right\}=1$ implies $\max \{a, b\}=1$. It is easy to prove also

$$
\begin{aligned}
\lim _{\substack{i, j \rightarrow \infty \\
i \neq j}}\left\|z_{n_{i}}-z_{n_{j}}\right\| & =\lim _{\substack{i, j \rightarrow \infty \\
i \neq j}} \max \left\{\left\|x_{n_{i}}-x_{n_{j}}\right\|,\left\|y_{n_{i}}-y_{n_{j}}\right\|\right\} \\
& \geq \max \{a \operatorname{WCS}(X), b \operatorname{WCS}(Y)\} \\
& \geq \min \{\operatorname{WCS}(X), \operatorname{WCS}(Y)\} .
\end{aligned}
$$

Hence, $\operatorname{WCS}(Z) \geq \min \{\operatorname{WCS}(X), \operatorname{WCS}(Y)\}$ for $1 \leq p \leq \infty$, and the proof is complete. [5]

Recalling that Maluta's coefficient $D(X)$ of a Banach space $X$ is defined by $D(X)=\sup \left\{\frac{\lim \sup d\left(x_{n+1}, \operatorname{co}\left(\left\{x_{j}\right\}_{1}^{n}\right)\right.}{\operatorname{diam}\left(\left\{x_{n}\right\}\right)}:\left\{x_{n}\right\}\right.$ a bounded nonconstant sequence in $X\}$ and $\operatorname{WCS}(X)=1 / D(X)$ for reflexive space $X$ [6], we obtain immediately Corollary 1. Let $1 \leq p \leq \infty, Z=\left(\prod_{i=1}^{n} X_{i}\right)_{l_{p}}$, and all $X_{i} \quad(1 \leq i \leq n)$ be reflexive Banach spaces. Then

$$
D(Z)=\max \left\{D\left(X_{i}\right): 1 \leq i \leq n\right\} .
$$

Remark 2. When Landes discussed permanence properties of normal structures under a finite product of Banach spaces, he showed that [7] if both $X$ and $Y$ are reflexive spaces and $\operatorname{WCS}(X), \operatorname{WCS}(Y)>1$, then $Z=(X \times Y)_{l_{1}}$ has the normal structure. Applying our Theorem 5, in fact, we can obtain $\operatorname{WCS}(Z)>1$, which implies that $Z$ has the normal structure.

\section{REFERENCES}

1. W. L. Bynum, Normal structure coefficient for Banach spaces, Pacific J. Math. 86 (1980), 427-436.

2. T. C. Lim, On the normal structure coefficient and the bounded sequence coefficient, Proc. Amer. Math. Soc. 88 (1983), 262-264.

3. V. I. Istrătescu, On a measure of noncompactness, Bull. Math. Soc. Sci. Math. R. S. Roumanie 16 (1972), 195-197.

4. C. A. Kottmann, Subsets of the unit ball that are separated by more than one, Studia Math. 53 (1975), 15-27. 
5. E. Maluta, Uniformly normal structure and related coefficients, Pacific J. Math. 111 (1984), 357-369.

6. Hong-Kun $\mathrm{Xu}$, On the Maluta's problem of sequence constants in Banach spaces, Bull. Sci. China 34 (1989), 725-726. (Chinese)

7. T. Landes, Permanence properties of normal structure, Pacific J. Math. 110 (1984), 125-143.

Department of Mathematics \& Physics, University of Petroleum, Dongying City, Shandong, People's Republic of China 